\title{
Multibreed genetic evaluation in bovines using simulated data employing a composite population
}

\author{
A.L. Bocchi ${ }^{1}$, H.N. Oliveira ${ }^{2}$, J.B.S. Ferraz ${ }^{3}$ and J.P. Eler ${ }^{3}$ \\ ${ }^{1}$ Departamento de Zootecnia, Escola de Veterinária e Zootecnia, \\ Universidade Federal de Goiás, Campus Jataí, Jataí, GO, Brasil \\ ${ }^{2}$ Departamento de Zootecnia, Faculdade de Ciências Agrárias e Veterinárias, \\ Universidade Estadual Paulista, Jaboticabal, SP, Brasil \\ ${ }^{3}$ Departamento de Medicina Veterinária, \\ Faculdade de Zootecnia e Engenharia de Alimentos, Universidade de São Paulo, \\ Pirassununga, SP, Brasil \\ Corresponding author: A.L. Bocchi \\ E-mail: albocchi@hotmail.com
}

Genet. Mol. Res. 15 (4): gmr.15048382

Received January 4, 2016

Accepted February 26, 2016

Published October 5, 2016

DOI http://dx.doi.org/10.4238/gmr.15048382

Copyright (C) 2016 The Authors. This is an open-access article distributed under the terms of the Creative Commons Attribution ShareAlike (CC BY-SA) 4.0 License.

\begin{abstract}
Genetic evaluations in Brazil are performed within each animal breed; however, with the wide range of extant genetic groups in the country and the increased use of genetic crossing as a form of rapid meat production, more elaborate programs that can jointly evaluate animals of different genetic groups are needed. Genetic evaluation of a composite breed is difficult because of the variation in the genetic composition of a given herd, as well as the inclusion of non-additive genetic effects among breeds that can be important for selecting traits in certain breed combinations. Newer models include additive and nonadditive effects; however, few studies have investigated these aspects in
\end{abstract}


tropical breeds. The aim of this study was to simulate genetic values to compare different models. Non-inclusion of maternal effects in models leads to overestimation of variance and direct heritability. Estimates of the biological additive effects are influenced by the maternal effects; however, estimates of the non-additive effects are minimally influenced by the maternal effects and are well estimated in any situation. The studied models effectively predict the direct genetic values.

Key words: Beef cattle; Genetic parameters; Heterosis; Least squares; Maternal effect

\section{INTRODUCTION}

Crossbreeding systems are important tools for high meat production. For best results, these systems should be carefully planned and should always include animals with superior additive genetic effects. Many studies have highlighted the influence of non-additive effects on the performance of crossbred animals (Quaas and Pollak, 1981; Arnold et al., 1992).

Mourão et al. (2008) evaluated the non-additive effects of heterosis on weaning weight at 205 days, yearling weight at 390 days, and weight-gain from the weaning stage to the yearling stage in a Brazilian Bos taurus x Bos indicus beef composite. According to these authors, it is important to consider these effects in genetic evaluations because of their contribution to animal productivity. However, the authors highlighted the need for further investigations and development of more complete models or other adjustment strategies. Using information from the same population as Mourão et al. (2008), with actualized animal data, Bueno et al. (2012) studied two models. In one model, the data were pre-adjusted for non-additive effects that considered the direct additive, maternal, and non-additive fixed genetic effects, the direct and total maternal heterozygosities, and epistasis. In the other genetic model, the non-additive effects were considered as covariates. The authors observed a correlation higher than 0.94 between the predicted breeding values, indicating that the bulls' rankings were not changed by the data correction for non-additive effects. It was concluded that the methods, which were evaluated, did not suggest changes in the selection of animals but indicated the need for an investigation of the non-additive effects of the studied population as well as for the inclusion of these effects in the genetic analysis.

Modeling non-additive effects is challenging because of the confusion and the consequent multicollinearity between these and other effects. Non-additive effects cause deviation in the genotypic value of heterozygotes compared with the average of that of homozygotes. Non-additive variance is caused by the interaction between the genes at the same locus (dominance and over-dominance) as well as the interaction between two or more genes at different loci (epistasis). In multibreed evaluation, non-additive genetic effects can be observed at three levels: breed (heterosis), mating (bull x mother's breed group), and the individual itself (within the breed).

Rodríguez-Almeida et al. (1997) applied the multibreed model of Arnold et al. (1992) in a simplified manner, using two data groups: the first included breeds that formed three composite breeds and the second included the sum of the first group plus experimental data with proper crossings and mating to promote a better structure for estimating the effects in a multibreed analysis. According to the authors, it is necessary to combine the experimental data

Genetics and Molecular Research 15 (4): gmr.15048382 
with the field data to satisfactorily estimate the effects on multibreed models.

Simulation is one method that can be used to perform a comparative analysis of different statistical methodologies or models. According to Pereira (2001), simulation makes it possible to generate genetic and residual values of a trait for a set of hypothetical or non-hypothetical animals. From these values, we can generate phenotypic data for the comparison of different methodologies.

Using a set of real data, simulation of the genetic values of the animals allows for a comparison between the proposed models. The model that is more adapted to the existing data structure can then be further verified.

The aim of the present research was to study the simulated data, including additive and non-additive effects, as well as direct and maternal effects, to compare and identify the models that are better adapted to these data with the aim of obtaining more accurate genetic values.

\section{MATERIAL AND METHODS}

\section{Data origin}

Data from a population of 84,621 animals distributed in 1549 contemporary groups (CGs) with a relationship matrix of 154,417 animals were used for the simulation of average daily weight gain from birth to weaning (ADG; Bocchi et al., 2008). The breeds were grouped into four biological types (BT) according to Ferraz et al. (1999): N (Zebu), A (Adapted), B (British), and C (Continental).

The proportion of each BT in the genetic composition of the animals was calculated from the breed composition of the animal and from the breed composition of the mother, yielding the following variables: $\mathrm{PN}, \mathrm{PA}, \mathrm{PB}, \mathrm{PC}, \mathrm{MN}, \mathrm{MA}, \mathrm{MB}$, and $\mathrm{MC}$, where $\mathrm{BT}=\mathrm{N}, \mathrm{A}$, $\mathrm{B}$, and $\mathrm{C}, \mathrm{PBT}=$ proportion of the $\mathrm{BT}$, and $\mathrm{MBT}=$ proportion of the $\mathrm{BT}$ of the mother. The heterozygosis was estimated for each combination of BTs in the animals using the product of the genetic proportion related to the BT of the mother (MBT) and that of the father (FBT), yielding the following variables: $\mathrm{HNA}, \mathrm{HNB}, \mathrm{HNC}, \mathrm{HAB}, \mathrm{HAC}$, and, $\mathrm{HBC}$, where $\mathrm{HBT}_{1} \mathrm{BT}_{2}$ $=$ expected heterozygosis obtained as the proportion of $\mathrm{MBT}_{1} \times \mathrm{FBT}_{2}+\mathrm{FBT}_{1} \times \mathrm{MBT}_{2}$.

The maternal heterozygosis variable was similarly estimated, generating the following variables: HMNA, HMNB, HMNC, HMAB, HMAC, and $\mathrm{HBMC}$, where $\mathrm{HMBT}_{1} \mathrm{BT}_{2}=$ expected heterozygosis, obtained as the proportion of $\mathrm{MMBT}_{1} \times \mathrm{FMBT}_{2}+\mathrm{FMBT}_{1} \times \mathrm{MMBT}_{2}$. MMBT and FMBT were related to the mother and father of the animal's mother, respectively.

\section{Statistical analysis}

Because of the structural complexity of the population in the breed-set and taking into consideration the possibility of the confusion between the different effects included in the model, a simulation study was performed to determine the best model for each possible situation. For this simulation, we used the same pedigree structure and data distribution of the data file that had been used in the analysis with the observed data. The average of the data on daily weight gain from birth to weaning was analyzed.

The simulation was performed using the Interactive Matrix Language procedure of the statistical analysis program SAS (SAS Institute, 2004), using the pedigree information, breed composition of the animals, and direct heterozygosis as well as the medium, direct, and maternal variances. The genetic, environmental, and phenotypic values were simulated,

Genetics and Molecular Research 15 (4): gmr.15048382 
including the additive breed genetic effects and heterosis. Furthermore, the maternal breed effects and maternal heterosis were simulated, yielding three types of simulated data files: File 1 consisting of additive breed and heterosis effects; File 2 consisting of additive breed, heterosis, and maternal breed effects; and File 3 consisting of additive breed, heterosis, maternal breed, and maternal heterosis effects. The genetic values (direct and maternal) were simulated for the founder animals (pure breeds), taking into consideration the existence of a genetic additive effect for each BT. Based on the genetic values of the founder animals, the genetic values of the descendants were estimated as half of the genetic value of the parents added to the simulation of the resulting fraction of the Mendelian segregation.

The three data files were simulated using four different parameter groups. For each group, five replicates were used. These groups were called S1, S2, S3, and S4. The averages of the estimates for each group were calculated using the replicates.

A one-trait analysis was performed by taking into consideration a set of fixed effects (CG, calving order, and individual and maternal heterosis) and random effects (direct genetic additive, maternal, and residual effects). The analysis was performed in two stages.

In the first stage, which was primarily aimed at obtaining an estimate of the direct and maternal non-additive effects (heterosis), the analysis was performed using the least squares estimation method, with linear models including only the fixed effects. The general linear model (GLM) procedure of the SAS software (2004) was used, and three models were tested, including the effects of CG and calving order: Model 1 tested the additive breed and heterosis effects; Model 2 tested the breed additive, heterosis, and maternal breed effects; Model 3 tested the breed additive, heterosis, maternal breed, and maternal heterosis effects.

The additive genetic effect of each BT was estimated as the partial regression coefficient of the proportion of the BT that was present in the breed composition of the animal in the case of direct effect or in the breed composition of its mother in the case of maternal effect.

The least square solutions were obtained and the data were adjusted for direct and maternal heterosis effects, depending on the model that was used. The estimation of these effects and the adjustment of the data before the final analysis aimed to reduce the variability caused by the heterosis, without interfering with the additive effects. Thus, individual additive genetic values were predicted without the interference of non-additive effects.

In the second stage, the analysis was performed using MTDFREML (Boldman et al., 1995). The analyzed variable, ADG, was adjusted for non-additive effects, according to the results of the first stage. Estimates of the components of variances and of genetic parameters were obtained using the restricted maximum likelihood procedure and the free derivate algorithm, using the animal model. For this analysis, two models were used: In Model 1 the direct additive genetic effects were taken into consideration, and in Model 2, the additive genetic effects as well as direct and maternal effects were taken into consideration. Combining the simulation and the used models, 18 analyses were performed.

These models evaluated the capacity to separate the non-additive effects of heterosis (direct and maternal) and the direct and maternal additive effects, according to the relative proportion of each biological type.

In a matrix, the model can be represented by $\mathrm{y}=\mathrm{Xb}+\mathrm{Za}+\mathrm{Wm}+\mathrm{e}$, where $\mathrm{y}=$ preset observation vector for the non-additive heterozygosis effects; $b=$ fixed effects vector; $a=$ random direct genetic-additive effects vector; $\mathrm{m}=$ maternal random genetic-additive effects vector; $\mathrm{e}=$ residual random effect vector; $\mathrm{X}, \mathrm{Z}$, and $\mathrm{W}=$ incidence matrices of the effects associated with the elements $b$, a, and $m$, respectively.

Genetics and Molecular Research 15 (4): gmr.15048382 


\section{Comparison between the models}

The criteria that were used to evaluate the prediction capacity of the 18 sets of parameters obtained by the studied models were based on the results of the estimates of the variance and heritability components and the regression analysis between the estimated genetic values (EVd and EVm - direct and maternal), using the GLM and SAS/INSIGHT procedures.

\section{RESULTS AND DISCUSSION}

The parameters that were used for each simulation are presented in Table 1. The parameters for the following effects displayed deviations from the average: additive breed, maternal breed, and individual and maternal heterosis effects.

Table 1. Parameter groups (S1, S2, S3, and S4) used for simulation of average daily weight gain from birth to weaning (ADG).

\begin{tabular}{|c|c|c|c|c|}
\hline \multirow[t]{2}{*}{ Parameters } & \multicolumn{4}{|c|}{ Values } \\
\hline & S1 & $\mathrm{S} 2$ & S3 & $\mathrm{S} 4$ \\
\hline$\sigma_{\mathrm{a}}$ & $55 \mathrm{~g}$ & $55 \mathrm{~g}$ & $55 \mathrm{~g}$ & $55 \mathrm{~g}$ \\
\hline$\sigma_{\mathrm{m}}$ & $20 \mathrm{~g}$ & $20 \mathrm{~g}$ & $20 \mathrm{~g}$ & $20 \mathrm{~g}$ \\
\hline$\sigma_{\mathrm{e}}$ & $75 \mathrm{~g}$ & $75 \mathrm{~g}$ & $75 \mathrm{~g}$ & $75 \mathrm{~g}$ \\
\hline Average & $425 \mathrm{~g}$ & $425 \mathrm{~g}$ & $425 \mathrm{~g}$ & $425 \mathrm{~g}$ \\
\hline $\mathrm{PN}$ & $-45 \mathrm{~g}$ & $-45 \mathrm{~g}$ & $-45 \mathrm{~g}$ & $-45 \mathrm{~g}$ \\
\hline $\mathrm{PA}$ & $-55 \mathrm{~g}$ & $-55 \mathrm{~g}$ & $-55 \mathrm{~g}$ & $-55 \mathrm{~g}$ \\
\hline PB & $-15 \mathrm{~g}$ & $-15 g$ & $-15 \mathrm{~g}$ & $-15 \mathrm{~g}$ \\
\hline $\mathrm{PC}$ & $115 \mathrm{~g}$ & $115 \mathrm{~g}$ & $115 \mathrm{~g}$ & $115 \mathrm{~g}$ \\
\hline $\mathrm{MN}$ & $-25 \mathrm{~g}$ & $5 \mathrm{~g}$ & $-10 \mathrm{~g}$ & $-10 \mathrm{~g}$ \\
\hline MA & $-15 \mathrm{~g}$ & $35 \mathrm{~g}$ & $35 \mathrm{~g}$ & $20 \mathrm{~g}$ \\
\hline MB & $25 \mathrm{~g}$ & $-10 \mathrm{~g}$ & $5 \mathrm{~g}$ & $5 \mathrm{~g}$ \\
\hline $\mathrm{MC}$ & $5 \mathrm{~g}$ & $-30 \mathrm{~g}$ & $-30 \mathrm{~g}$ & $-15 \mathrm{~g}$ \\
\hline HNA & $-85 \mathrm{~g}$ & $-65 \mathrm{~g}$ & $-65 g$ & $-65 \mathrm{~g}$ \\
\hline HNB & $35 \mathrm{~g}$ & $55 \mathrm{~g}$ & $55 \mathrm{~g}$ & $55 \mathrm{~g}$ \\
\hline $\mathrm{HNC}$ & $75 \mathrm{~g}$ & $85 \mathrm{~g}$ & $85 \mathrm{~g}$ & $85 \mathrm{~g}$ \\
\hline HAB & $-125 g$ & $-65 g$ & $-65 g$ & $-65 \mathrm{~g}$ \\
\hline HAC & $-45 \mathrm{~g}$ & $-15 \mathrm{~g}$ & $-15 \mathrm{~g}$ & $-15 \mathrm{~g}$ \\
\hline $\mathrm{HBC}$ & $-5 g$ & $5 \mathrm{~g}$ & $5 \mathrm{~g}$ & $5 \mathrm{~g}$ \\
\hline HMNA & $-35 \mathrm{~g}$ & $5 \mathrm{~g}$ & $5 \mathrm{~g}$ & $5 \mathrm{~g}$ \\
\hline HMNB & $-15 \mathrm{~g}$ & $-15 \mathrm{~g}$ & $-15 \mathrm{~g}$ & $-15 \mathrm{~g}$ \\
\hline HMNC & $25 \mathrm{~g}$ & $15 \mathrm{~g}$ & $15 \mathrm{~g}$ & $15 \mathrm{~g}$ \\
\hline HMAB & $-45 \mathrm{~g}$ & $-45 \mathrm{~g}$ & $-45 \mathrm{~g}$ & $-45 \mathrm{~g}$ \\
\hline HMAC & $10 \mathrm{~g}$ & $5 \mathrm{~g}$ & $5 \mathrm{~g}$ & $5 \mathrm{~g}$ \\
\hline HMBC & $55 \mathrm{~g}$ & $35 \mathrm{~g}$ & $35 \mathrm{~g}$ & $35 \mathrm{~g}$ \\
\hline
\end{tabular}

Average $=425 \mathrm{~g} ; \mathrm{s}_{\mathrm{a}}=$ direct genetic deviation pattern; $\mathrm{s}_{\mathrm{m}}=$ maternal genetic deviation pattern; $\mathrm{s}_{\mathrm{e}}=$ phenotypic deviation pattern; BT $=\mathrm{N}$ (Zebu), A (Adapted), $\mathrm{B}$ (British), and $\mathrm{C}$ (Continental); $\mathrm{PBT}=$ average daily weight gain from birth to weaning values of the relative breed proportion of biological types of $\mathrm{BT}$; $\mathrm{MBT}=$ proportion of $\mathrm{BT}$ of the mother; FBT = proportion of BT of the father; $\mathrm{HNA}, \mathrm{HNB}, \mathrm{HNC}, \mathrm{HAB}, \mathrm{HAC}$, and $\mathrm{HBC}$, where $\mathrm{HBT}_{1} \mathrm{BT}_{2}$ $=$ expected heterozygosis by the proportion of $\mathrm{MBT}_{1} \times \mathrm{FBT}_{2}+\mathrm{FBT}_{1} \times \mathrm{MBT}_{2}$; MMBT $=$ proportion of $\mathrm{BT}$ of the mother of the animal's mother; FMBT = proportion of BT of the father of the animal's mother; HMNA, HMNB, $\mathrm{HMNC}, \mathrm{HMAB}, \mathrm{HMAC}$, and $\mathrm{HBMC}$, where $\mathrm{HMBT}_{1} \mathrm{BT}_{2}=$ expected heterozygosis by the proportion of MMBT $\mathrm{x} \mathrm{FMBT}_{2}+\mathrm{FMBT}_{1}$ x MMBT 2 .

Combining the simulation and the used models, 18 analyses were performed, and the observations are presented in Table 2. 
Table 2. Simulated data files and models used for the analysis of average daily weight gain from birth to weaning.

\begin{tabular}{l|c|c|c}
\hline Analysis & Simulated data file & 1st Stage models & 2nd Stage models \\
\hline A111 & 1 & 1 & 1 \\
\hline A211 & 2 & 1 & 1 \\
\hline A311 & 3 & 1 & 1 \\
\hline A121 & 1 & 2 & 1 \\
\hline A221 & 2 & 2 & 1 \\
\hline A321 & 3 & 2 & 1 \\
\hline A131 & 1 & 3 & 1 \\
\hline A231 & 2 & 3 & 2 \\
\hline A331 & 3 & 3 & 2 \\
\hline A112 & 1 & 1 & 2 \\
\hline A212 & 2 & 1 & 2 \\
\hline A312 & 3 & 1 & 2 \\
\hline A122 & 1 & 2 & 2 \\
\hline A222 & 2 & 2 & 2 \\
\hline A132 & 3 & 2 & 2 \\
\hline A232 & 1 & 3 & \\
\hline A332 & 2 & 3 & \\
\hline & 3 & 3 & \\
\hline
\end{tabular}

The descriptive statistics that were obtained for ADG are presented in Table 3. Notably, although the fixed effects of CG and calving order were included in the models, they were not simulated.

Table 3. Average, determination coefficient $\left(\mathrm{R}^{2}\right)$, variation coefficient (CV), and deviation pattern (DP) of average daily weight gain from birth to weaning in each simulation set and model in the 1 st stage.

\begin{tabular}{|c|c|c|c|c|c|c|c|c|c|c|}
\hline \multirow[t]{2}{*}{ Parameters } & \multirow[t]{2}{*}{ Sim set } & \multicolumn{9}{|c|}{ Analysis } \\
\hline & & A11 & A21 & A31 & A12 & A22 & A32 & A13 & A23 & A33 \\
\hline \multirow[t]{4}{*}{$\mathrm{R}^{2}(\%)$} & S1 & 39.2 & 32.8 & 36.7 & 39.2 & 32.9 & 38.1 & 39.2 & 32.9 & 38.3 \\
\hline & S2 & 32.5 & 32.0 & 35.7 & 32.6 & 32.2 & 35.8 & 32.6 & 32.2 & 35.9 \\
\hline & S3 & 31.9 & 29.0 & 32.6 & 31.9 & 29.1 & 32.6 & 32.0 & 29.1 & 32.8 \\
\hline & S4 & 31.7 & 28.4 & 32.4 & 31.7 & 28.5 & 32.5 & 31.7 & 28.5 & 32.6 \\
\hline \multirow[t]{4}{*}{ CV (\%) } & S1 & 25.7 & 27.3 & 27.7 & 25.7 & 27.3 & 27.6 & 25.7 & 27.3 & 27.6 \\
\hline & S2 & 23.6 & 24.5 & 24.7 & 23.6 & 24.4 & 24.6 & 23.6 & 24.4 & 24.6 \\
\hline & S3 & 23.8 & 25.1 & 25.3 & 23.8 & 25.1 & 25.3 & 23.8 & 25.1 & 25.3 \\
\hline & S4 & 23.6 & 24.8 & 25.3 & 23.6 & 24.8 & 25.0 & 23.6 & 24.8 & 25.0 \\
\hline \multirow{4}{*}{ DP (g) } & S1 & 92.0 & 95.3 & 95.9 & 92.0 & 95.3 & 95.4 & 92.0 & 95.3 & 95.3 \\
\hline & S2 & 92.0 & 95.3 & 95.4 & 92.0 & 95.2 & 95.3 & 92.0 & 95.1 & 95.2 \\
\hline & S3 & 92.0 & 95.3 & 95.4 & 92.0 & 95.3 & 95.4 & 92.0 & 95.3 & 95.3 \\
\hline & S4 & 91.9 & 95.3 & 95.4 & 91.9 & 95.3 & 95.3 & 91.9 & 95.3 & 95.3 \\
\hline \multirow[t]{4}{*}{ Average (g) } & S1 & 357.3 & 348.4 & 345.2 & 357.3 & 348.4 & 345.2 & 357.3 & 348.4 & 345.2 \\
\hline & S2 & 389.9 & 389.4 & 386.6 & 389.9 & 389.4 & 386.6 & 389.9 & 389.4 & 386.6 \\
\hline & S3 & 386.0 & 379.5 & 376.6 & 386.0 & 379.4 & 376.6 & 386.0 & 379.4 & 376.6 \\
\hline & S4 & 388.5 & 383.3 & 380.5 & 388.5 & 383.3 & 380.5 & 388.4 & 383.3 & 380.5 \\
\hline
\end{tabular}

$\mathrm{A} 1 \mathrm{x}, \mathrm{A} 2 \mathrm{x}, \mathrm{A} 3 \mathrm{x}=$ simulated data file of average daily weight gain from birth to weaning; Ax1, Ax2, Ax3 = models 1,2 , and 3 in the 1st stage; S1, S2, S3, and S4 = simulation sets.

Inclusion of maternal breed effects in the simulation considerably influenced the determination coefficient $\left(\mathrm{R}^{2}\right)$, by reducing the $\mathrm{R}^{2}$. However, the model could not explain the observed variation. When the maternal heterosis effect was also included in the simulation, the $\mathrm{R}^{2}$ increased irrespective of the inclusion of the maternal effects in the model. It is interesting to

Genetics and Molecular Research 15 (4): gmr.15048382 
note that the $\mathrm{R}^{2}$, as well as other parameters that are presented in Table 3, were more dependent on the simulation than on the model used for analysis.

The contemporary group effect was not included in the simulation. However, this effect was included in the model and represented a greater proportion of the total sum of squares. This result indicated that the inclusion of more than one genetic composition in the contemporary groups was insufficient to avoid confusion between CG and genetic effects. In particular, these effects might be confused with the two types of maternal effects. Although there was consistency in preventing the contemporary groups from being composed of animals of only one genetic composition, the same was not achieved with respect to the genetic composition of the mother.

\section{Additive breed effects of the biological types}

Figure 1 illustrates the estimates of the breed effects of the BTs for the ADG-simulated data and expresses the estimates as deviations of BTN for the simulation sets S1, S2, S3, and S4.
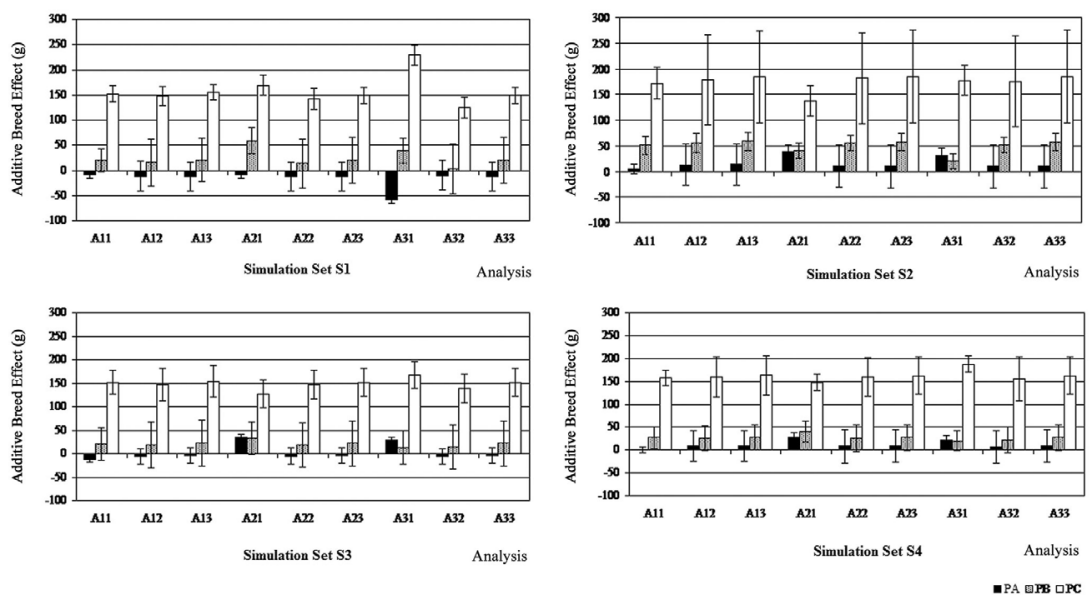

Figure 1. Estimates of the additive breed effects of the relative breed proportions of the biological types Zebu (PN), Adapted (PA), British (PB), and Continental (PC). The estimates are expressed as deviations from PN for models 1, 2, and 3 in the first stage (Ax1, Ax2, and Ax3) for each simulated data file (A1x, A2x, and A3x) of average daily weight gain from birth to weaning (ADG). Bovines from the simulation sets 1, 2, 3, and 4 (S1, S2, S3 and S4) were included.

The figure also presents the standard deviations for each estimated value calculated from the five repetitions. The deviations were high and sometimes higher than the estimates, as can also be observed in Figure 1. The fact that the deviations were high suggests that a considerable part of the variation that was observed in the estimates could be attributed to the process of randomization of the genetic values of the founder animals, as the number of non-Zebu bulls was not large. However, the estimates showed similar trends. Although the parameters used in the four sets of simulated data (S1, S2, S3, and S4) for PN, PA, PB, and $\mathrm{PC}$ were equal, the estimates of additive breed effects differed with respect to the amplitude and classification. Among the sets of simulated data, there was a change in parameters for the maternal breed effects. These changes might have influenced the variation among the estimates of PN, PA, PB, and PC.

The estimates of PB and PC were closer to the parameters used in the S4 simulation.

Genetics and Molecular Research 15 (4): gmr.15048382 
However, the PA values were more similar to those used in the S1 simulation.

In all the simulated data groups ( $\mathrm{S} 1$ to $\mathrm{S} 4$ ), the behavior of the estimates was similar for the analysis, in general. The analyses in which the maternal effect was incorporated into the simulation and not into the model (A21 and A31) were an exception, possibly because the estimate generated by this model was contaminated by the maternal effect. For all the other cases, the results were similar, regardless of whether the model included the simulated effect or not.

In S1, for all the analysis groups, the PA values were lower than the PN values, with more evidence in A31, demonstrating the influence of the maternal effects on that estimate when they were not taken into consideration in the analysis model. The standard deviations were very high for PA and PB compared to PC. In this simulation, values of $10 \mathrm{~g}$ for MA, 50 $\mathrm{g}$ for $\mathrm{MB}$, and $30 \mathrm{~g}$ for $\mathrm{MC}$ were used when compared with $\mathrm{MN}$ as a parameter. It is possible that the lower values of MA influenced the low estimates of PA.

In the $\mathrm{S} 2$ group, the PA values were higher than the $\mathrm{PN}$ values and were generally lower than the PB values, with the exception of A21 and A31, which were similar. For the simulations that also included the maternal effect, it is possible that because there were no purebred animals with records of simulated production, the estimated values for the BT effects might have included a basal level of maternal heterozygosis or maternal effect.

This simulation used the parameters $30 \mathrm{~g}$ for MA, $-15 \mathrm{~g}$ for $\mathrm{MB}$, and $-35 \mathrm{~g}$ for $\mathrm{MC}$ for maternal breed effects compared with $\mathrm{MN}$, with inversion in the ranking compared to S1. It appears that the maternal effects influenced PA differently than PB and PC; use of maternal effects with higher values in the simulation positively influenced $\mathrm{PA}$, and maternal effects with lower values positively influenced $\mathrm{PB}$ and $\mathrm{PC}$.

In S3, the estimates of PA were lower than PN, with the exception of the models that did not include the maternal effect when included in the simulation (A21 and A31). Additionally, in these two cases, PA was positive relative to PN. The parameters that were used for the simulation of additive maternal effect were $45 \mathrm{~g}$ for MA, $15 \mathrm{~g}$ for $\mathrm{MB}$, and $-20 \mathrm{~g}$ for $\mathrm{MC}$ compared to $\mathrm{MN}$. The higher values of $\mathrm{MB}$ and $\mathrm{MC}$ when compared with $\mathrm{S} 2$ seem to have influenced the estimates of $\mathrm{PB}$ and $\mathrm{PC}$, which were closer to those found in S1. However, the standard deviations were much higher for the PB estimates. It appears that there was an interaction between the additive direct and maternal effects in which a change in one or more influenced the others.

In S4, the estimates of PA were higher than those of PN and, as in S2 and S3, had values similar to $\mathrm{PB}$ in $\mathrm{A} 21$ and $\mathrm{A} 31$. In this case, the parameters of simulation of $30 \mathrm{~g}$ for MA, $15 \mathrm{~g}$ for $\mathrm{MB}$, and $-5 \mathrm{~g}$ for $\mathrm{MC}$ were used. Although the MA value was equal to that used in $\mathrm{S} 2$, the values for $\mathrm{MB}$ and $\mathrm{MC}$ were much higher, most likely influencing the PA estimates similar to S2; the values of PB and PC were slightly higher than those of S1. However, the deviation values for $\mathrm{PC}$ were higher.

It is interesting to note, however, that the similarities between the estimates for each simulation group were independent of whether the model included the simulated maternal effect.

The values of the maternal effects also appeared to considerably influence the variation between the estimates of the same simulation, as evidenced by the large standard deviations of the estimates between the different simulation groups.

\section{Maternal breed effects of the biological types}

The estimates for the maternal breed effects of the biological types are presented in Figure 2 for the simulated data of ADG and are expressed as deviations of MN.

Genetics and Molecular Research 15 (4): gmr.15048382 

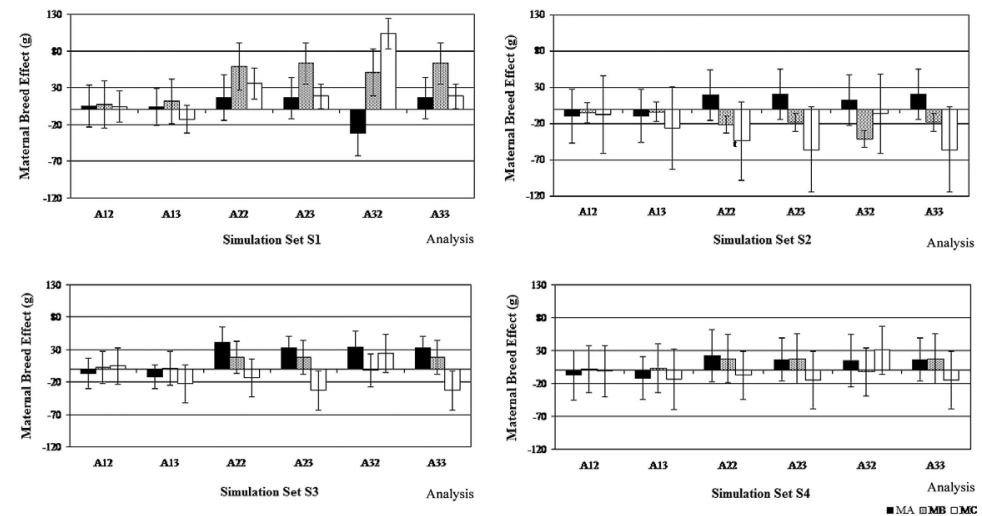

Figure 2. Estimates of the maternal breed effects of the relative breed proportions of the biological types Zebu (MN), Adapted (MA), British (MB), and Continental (MC). The estimates are expressed as deviations from MN for models 2 and 3 in the first stage (Ax2 and Ax3) for each simulated data file (A1x, A2x, and A3x) of average daily weight gain from birth to weaning. Bovines from the simulation sets 1, 2, 3, and 4 (S1, S2, S3, and S4) were included.

The estimates for the maternal breed effects were close to the parameters used in the simulations in the models that included the maternal effects corresponding to the simulated effects (A22, A23, and A33). In A32, in which the maternal heterosis effect was not simulated but was included in the model, the estimates were very distinct. In the situations in which the maternal effects were not simulated (A12 and A13), the estimates were much closer to zero. The maternal breed effect estimates varied more within a simulation than the additive breed effects, such as the high standard deviation values.

As shown in Figure 2, in all the simulation sets ( $\mathrm{S} 1$ to $\mathrm{S} 4$ ), the estimates for MA, $\mathrm{MB}$, and $\mathrm{MC}$ relative to those for $\mathrm{MN}$ were similar among A22, A23, and A33, with values corresponding to the simulated data. This result indicated that the model might be adequate for the analyzed data structure; for the other models, the estimates were considerably different from the expected values. The estimates of MA for A12 and A13 were low in S1 and were lower than $\mathrm{MN}$ in the other groups. In the same analysis, the estimates of MB were nearly equal to those of MN. However, MC, with the exception of S1, showed the same trend as the estimates obtained in the other analysis. In A32 (simulation of breed effects and maternal heterosis and inclusion only in the maternal breed model), the behavior of the obtained estimates for the three breed compositions was considerably variable among the simulation sets and did not follow a standard pattern.

\section{Individual heterosis effects}

Figure 3 presents the estimates of the heterosis effects obtained by the analysis of variance of the models for the simulated data of ADG.

Comparing the established ADG values for the individual heterosis effects used to simulate these effects, the estimates were consistent with the established values and did not vary significantly among the analyses. Only the estimates for HBC differed considerably among the simulation sets, although variation might exist because the values of $\mathrm{HBC}$ used in the simulation were very low. As shown in Figure 3, the behavior of the estimates was better visualized according to the simulation set (S1 to S4).

Genetics and Molecular Research 15 (4): gmr.15048382 

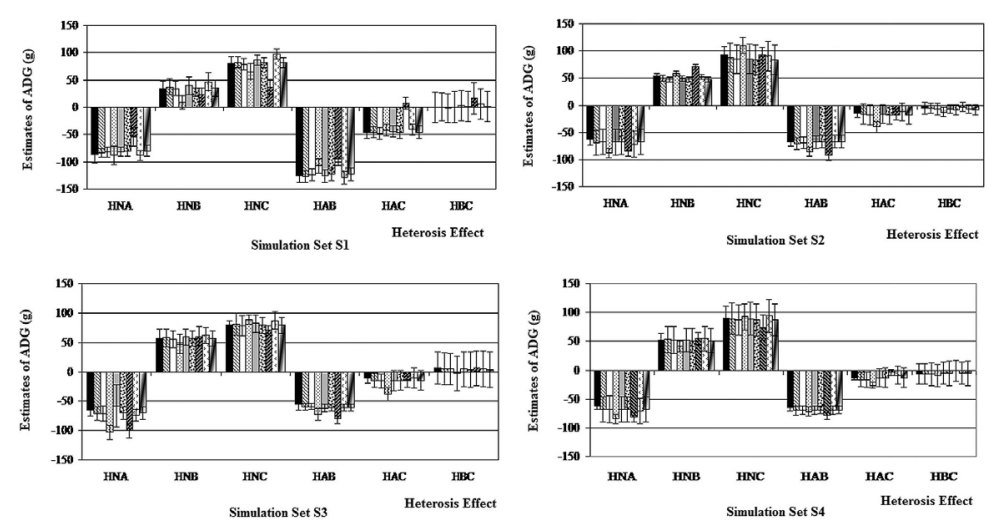

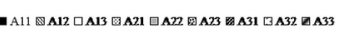

Figure 3. Estimates of the heterosis effects for models 1,2 , and 3 in the first stage $(A x 1, A x 2$, and $A x 3)$ for each simulated data file (A1x, A2x, and $\mathrm{A} 3 \mathrm{x}$ ) of average daily weight gain from birth to weaning (ADG). Bovines from the simulation sets $1,2,3$, and 4 (S1, S2, S3, and S4) were included.

Figure 3 illustrates that the estimates were very similar among the analyses. In A21 and A31 (and occasionally in A32), the estimates deviated slightly relative to the others. A similar observation was noted for the estimates of the additive effects, albeit with much less variation. The HNA estimates exhibited high standard deviations in S2 and S4, HNB only in $\mathrm{S} 4, \mathrm{HNC}$ in S2 and S4, and HBC in S1, S3, and S4. Evidently, the estimates of the heterosis effect were not considerably influenced by changes in the parameters of maternal additive effects that were used in the simulation.

\section{Maternal heterosis effects}

The estimates of the maternal heterosis effects obtained by analysis of variance of the models for the ADG simulated data are presented in Figure 4.
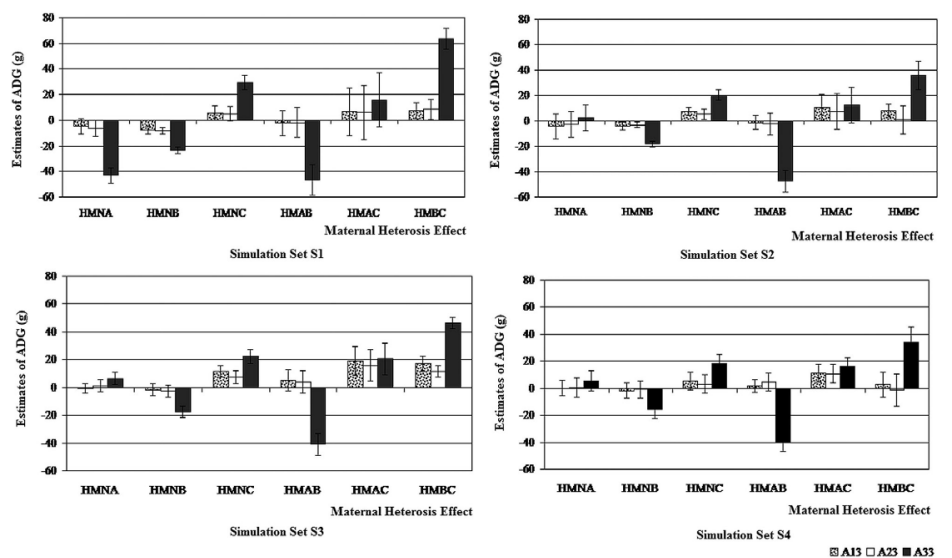

Figure 4. Estimates of the maternal and maternal heterosis effects for model 3 in the first stage (Ax3) for each simulated data file (A1x, A2x, A3x) of average daily weight gain from birth to weaning (ADG). Bovines from the simulation sets $1,2,3$, and 4 (S1, S2, S3, and S4) were included.

Genetics and Molecular Research 15 (4): gmr.15048382 
In the maternal heterosis estimates, the difference between the models was strongly evident. In A33, the estimates were very similar to the parameters used in the simulation, with the exception of the values of HMAC, which were three- to four-fold higher than the parameters.

As shown in Figure 4, the estimates were observed to change considerably among the analyses, demonstrating the importance of the non-additive maternal effect. In analyses, A13 and A23, the maternal heterosis effects, were not taken into consideration in the simulation. Therefore, the values of the estimates were closer to zero. With the effect included in the simulation, the estimates became more pronounced and closer to the utilized parameters. Apparently, the changes in the values of maternal breed effects among the simulations did not influence these estimates.

\section{Estimates of variance components and genetic parameters}

Regardless of the presence and importance of non-additive effects in multibreed populations, determination of these effects is very complicated due to confusion between the many effects. Data simulation can be used to obtain better results by comparing the true genetic values that were simulated (SV) with the estimated genetic values (EV).

The estimated variances and heritability for the direct and maternal additive effects according to the analysis and simulation set are presented in Tables 4 and 5.

Table 4. Estimated variances obtained to compare the mixed linear models according to each analysis group and simulation set.

\begin{tabular}{|c|c|c|c|c|c|c|c|c|c|c|c|c|}
\hline \multirow[t]{4}{*}{ Analysis } & \multicolumn{12}{|c|}{ Simulation set } \\
\hline & \multicolumn{3}{|c|}{ S1 } & \multicolumn{3}{|c|}{ S2 } & \multicolumn{3}{|c|}{ S3 } & \multicolumn{3}{|c|}{ S4 } \\
\hline & \multicolumn{12}{|c|}{ Estimates } \\
\hline & $\sigma_{\mathrm{a}}^{2}$ & $\sigma_{\mathrm{e}}^{2}$ & $\sigma_{\mathrm{m}}^{2}$ & $\sigma_{a}^{2}$ & $\sigma_{\mathrm{e}}^{2}$ & $\sigma^{2} \mathrm{~m}$ & $\sigma_{\mathrm{a}}^{2}$ & $\sigma_{\mathrm{e}}^{2}$ & $\sigma^{2} \mathrm{~m}$ & $\sigma_{\mathrm{a}}^{2}$ & $\sigma_{\mathrm{e}}^{2}$ & $\sigma_{\mathrm{m}}^{2}$ \\
\hline A111 & 3469 & 5353 & - & 3515 & 5359 & - & 3655 & 5257 & - & 3485 & 5382 & - \\
\hline A211 & 4989 & 4848 & - & 4676 & 5050 & - & 4835 & 4939 & - & 4817 & 4975 & - \\
\hline $\mathrm{A} 311$ & 5759 & 4473 & - & 4983 & 4898 & - & 5131 & 4791 & - & 5132 & 4818 & - \\
\hline A121 & 3474 & 5351 & - & 3542 & 5344 & - & 3635 & 5272 & - & 3478 & 5386 & - \\
\hline$\overline{\mathrm{A} 221}$ & 4914 & 4901 & - & 4794 & 4984 & - & 4936 & 4896 & - & 4840 & 4961 & - \\
\hline A321 & 5580 & 4642 & - & 5150 & 4827 & - & 5197 & 4772 & - & 5187 & 4808 & - \\
\hline$\overline{\mathrm{A} 131}$ & 3400 & 5384 & - & 3468 & 5376 & - & 3532 & 5315 & - & 3431 & 5405 & - \\
\hline$\overline{\mathrm{A} 231}$ & 4866 & 4926 & - & 4757 & 4942 & - & 4852 & 4928 & - & 4820 & 4968 & - \\
\hline$\overline{\mathrm{A} 331}$ & 4866 & 4926 & - & 4757 & 5003 & - & 4852 & 4928 & - & 4820 & 4968 & - \\
\hline$\overline{\mathrm{A} 112}$ & 3438 & 5364 & 14 & 3478 & 5371 & 16 & 3599 & 5276 & 24 & 3430 & 5401 & 23 \\
\hline$\overline{\mathrm{A} 212}$ & 3743 & 5300 & 504 & 3393 & 5515 & 520 & 3488 & 5420 & 549 & 3368 & 5506 & 576 \\
\hline A312 & 4451 & 4934 & 544 & 3728 & 5349 & 512 & 3826 & 5253 & 537 & 3714 & 5335 & 568 \\
\hline A122 & 3399 & 5376 & 32 & 3437 & 5382 & 43 & 3560 & 5298 & 32 & 3423 & 5406 & 22 \\
\hline A222 & 3532 & 5400 & 559 & 3524 & 5413 & 543 & 3534 & 5363 & 601 & 3435 & 5466 & 568 \\
\hline A322 & 3180 & 5501 & 970 & 3611 & 5371 & 628 & 3628 & 5330 & 637 & 3469 & 5442 & 676 \\
\hline A132 & 3296 & 5417 & 47 & 3388 & 5402 & 36 & 3461 & 5338 & 32 & 3398 & 5416 & 14 \\
\hline A232 & 3490 & 5416 & 561 & 3501 & 5422 & 543 & 3520 & 4439 & 569 & 3470 & 5454 & 546 \\
\hline$\overline{\mathrm{A} 332}$ & 3490 & 5415 & 561 & 3501 & 5422 & 543 & 3520 & 5377 & 569 & 3470 & 5454 & 546 \\
\hline
\end{tabular}

$\mathrm{s}_{\mathrm{a}}^{2}=$ additive genetic variance; $\mathrm{s}_{\mathrm{m}}=$ maternal genetic variance; $\mathrm{s}_{\mathrm{e}}{ }_{\mathrm{e}}=$ residual variance; $\mathrm{A} 1 \mathrm{xx}, \mathrm{A} 2 \mathrm{xx}, \mathrm{A} 3 \mathrm{xx}=$ simulated data file of average daily weight gain from birth to weaning; $\mathrm{Ax} 1 \mathrm{x}, \mathrm{Ax} 2 \mathrm{x}, \mathrm{Ax} 3 \mathrm{x}=$ models 1,2 , and 3 in the 1st stage; Axx1, Axx2 = models 1 and 2 in the $2^{\text {nd }}$ stage; S1, S2, S3, and S4 = simulation sets.

The variance and heritability components obtained according to each analysis between the simulation sets (S1 to S4) did not exhibit significant variation. However, these parameters were related to the inclusion of the effects on simulation and the studied model differences when 
the maternal effect was incorporated or not (analyses A111 to A332). When the analysis models from the 1st and 2nd stages did not include maternal effects (Ax11), the heritability grew due to the inclusion of the effects on the simulation until it reached 0.56 . This result illustrates the contamination of the genetic values with the maternal effects. The estimates of direct heritability for the simulated dataset without maternal effects (analysis A1xx) varied very little due to the inclusion of maternal effects in the 1st or 2nd stages, being slightly lower in the cases in which the first stage included the additive maternal effects and in the cases analyzed in the 2nd stage with the model that included additive maternal effects (analyses A122 and A123). As expected, the estimates of maternal effect heritability were null for the set that was simulated without maternal effects (analysis A1x2). Clément et al. (2001) verified the same situation using data that were simulated only with direct effects. When the data were analyzed using a more complex model, the direct heritability was not biased and the maternal effects were estimated to be equal to zero.

\begin{tabular}{|c|c|c|c|c|c|c|c|c|}
\hline \multirow[t]{4}{*}{ Analysis } & \multicolumn{8}{|c|}{ Simulation set } \\
\hline & \multicolumn{2}{|c|}{ S1 } & \multicolumn{2}{|c|}{ S2 } & \multicolumn{2}{|c|}{ S3 } & \multicolumn{2}{|c|}{ S4 } \\
\hline & \multicolumn{8}{|c|}{ Estimates } \\
\hline & $\mathrm{h}^{2}$ & $\mathrm{~h}^{2} \mathrm{~m}$ & $\mathrm{~h}^{2}$ & $\mathrm{~h}^{2} \mathrm{~m}$ & $\mathrm{~h}^{2}$ & $\mathrm{~h}_{\mathrm{m}}^{2}$ & $\mathrm{~h}^{2}$ & $\mathrm{~h}^{2} \mathrm{~m}$ \\
\hline A111 & 0.39 & - & 0.40 & - & 0.41 & - & 0.39 & - \\
\hline A211 & 0.51 & - & 0.48 & - & 0.49 & - & 0.49 & - \\
\hline A311 & 0.56 & - & 0.50 & - & 0.52 & - & 0.51 & - \\
\hline A121 & 0.39 & - & 0.40 & - & 0.41 & - & 0.39 & - \\
\hline A221 & 0.50 & - & 0.49 & - & 0.50 & - & 0.49 & - \\
\hline $\mathrm{A} 321$ & 0.55 & - & 0.52 & - & 0.52 & - & 0.52 & - \\
\hline A131 & 0.39 & - & 0.39 & - & 0.40 & - & 0.39 & - \\
\hline A231 & 0.50 & - & 0.48 & - & 0.50 & - & 0.49 & - \\
\hline A331 & 0.50 & - & 0.48 & - & 0.50 & - & 0.49 & - \\
\hline $\mathrm{A} 112$ & 0.39 & 0.000 & 0.39 & 0.002 & 0.40 & 0.002 & 0.39 & 0.002 \\
\hline $\mathrm{A} 212$ & 0.39 & 0.052 & 0.36 & 0.056 & 0.37 & 0.058 & 0.36 & 0.062 \\
\hline A312 & 0.45 & 0.054 & 0.39 & 0.054 & 0.40 & 0.056 & 0.39 & 0.062 \\
\hline $\mathrm{A} 122$ & 0.39 & 0.002 & 0.39 & 0.006 & 0.40 & 0.004 & 0.39 & 0.002 \\
\hline A222 & 0.37 & 0.058 & 0.37 & 0.058 & 0.37 & 0.062 & 0.36 & 0.058 \\
\hline A322 & 0.33 & 0.100 & 0.37 & 0.066 & 0.38 & 0.066 & 0.36 & 0.072 \\
\hline A132 & 0.38 & 0.006 & 0.38 & 0.000 & 0.39 & 0.002 & 0.38 & 0.002 \\
\hline A232 & 0.37 & 0.060 & 0.37 & 0.056 & 0.37 & 0.060 & 0.37 & 0.058 \\
\hline A332 & 0.37 & 0.060 & 0.37 & 0.056 & 0.37 & 0.060 & 0.37 & 0.058 \\
\hline
\end{tabular}

$\mathrm{h}^{2}=$ heritability; $\mathrm{h}_{\mathrm{m}}^{2}=$ maternal heritability; A1xx, $\mathrm{A} 2 \mathrm{xx}, \mathrm{A} 3 \mathrm{xx}=$ simulated data file of average daily weight gain from birth to weaning; Ax1x, Ax2x, Ax3x= models 1, 2, and 3 in the $1^{\text {st }}$ stage; Axx1, Axx2 = models 1 and 2 in the $2^{\text {nd }}$ stage; $\mathrm{S} 1, \mathrm{~S} 2, \mathrm{~S} 3$, and $\mathrm{S} 4=$ simulation sets.

When the maternal effect is incorporated in the second-stage model, the behavior changes slightly. In A112, A212, and A312, the maternal effect was incorporated in the 2nd stage, but it was not taken into consideration in the estimation of the non-additive direct effects in the 1st stage. It is possible that this exclusion led to the increase in direct heritability in A312 even when the maternal heritability also increased. For the other analyses, for the value of variances and direct heritability, there was a decrease for the direct effect, whereas the maternal effect increased.

According to Clément et al. (2001), when the maternal effect is neglected in the simulated data analysis with the maternal effect, the direct heritability is overestimated, possibly doubling with respect to its value, when the additive direct and maternal effects are taken into consideration in the model. In this study, a similar situation was observed, as described above, but the value did not double. These results are consistent with those of Waldron et al. (1993)

Genetics and Molecular Research 15 (4): gmr.15048382 
and Näsholm and Danell (1996) using real data as well as with the results of Southwood et al. (1989) and Robinson (1996) using simulated data.

When the maternal effect is partially neglected, it is difficult to distinguish between the maternal effects and the contribution of the mother to the progeny's genotype when using an animal model, as the direct genetic variance is influenced by part of the maternal genetic variance (Clément et al., 2001).

\section{Comparison of the models}

The $\mathrm{R}^{2}$ values of the regressions are presented in Tables 6 and 7 (all animals), Tables 8 and 9 (animals with data), and Tables 10 and 11 (bulls). In all the situations, the $\mathrm{R}^{2}$ values were similar in S1, S2, S3, and S4, and were mostly between EVd x SVd. In the regressions between the maternal genetic values (predicted and simulated), higher variation occurred between the simulation sets (S1 to S4) and among the realized analysis.

Table 6. Determination coefficients of the regressions between the estimated and simulated genetic values (EVd x SVd) for each analysis and simulation set (S1 through S4), taking into consideration all the animals.

\begin{tabular}{|c|c|c|c|c|}
\hline \multirow[t]{2}{*}{ Combined analysis } & \multicolumn{4}{|c|}{ Simulation set } \\
\hline & S1 & S2 & S3 & S4 \\
\hline & \multicolumn{4}{|c|}{ EVd x SVd } \\
\hline A111 & 35.43 & 34.96 & 34.15 & 33.93 \\
\hline $\mathrm{A} 211$ & 31.59 & 30.09 & 29.08 & 30.02 \\
\hline $\mathrm{A} 311$ & 30.62 & 30.94 & 29.87 & 30.91 \\
\hline $\mathrm{A} 121$ & 35.33 & 34.66 & 34.13 & 34.02 \\
\hline$\overline{\mathrm{A} 221}$ & 31.38 & 30.85 & 29.46 & 30.48 \\
\hline $\mathrm{A} 321$ & 31.21 & 31.22 & 30.38 & 31.01 \\
\hline A131 & 34.95 & 34.18 & 33.46 & 33.64 \\
\hline A231 & 30.80 & 30.41 & 29.22 & 30.20 \\
\hline $\mathrm{A} 331$ & 30.80 & 30.41 & 29.22 & 30.20 \\
\hline A112 & 35.48 & 34.99 & 34.20 & 33.98 \\
\hline $\mathrm{A} 212$ & 34.26 & 31.72 & 30.69 & 31.69 \\
\hline $\mathrm{A} 312$ & 31.76 & 32.32 & 31.16 & 32.36 \\
\hline $\mathrm{A} 122$ & 35.39 & 34.71 & 34.15 & 34.09 \\
\hline A222 & 33.06 & 32.14 & 30.71 & 32.05 \\
\hline $\mathrm{A} 322$ & 33.20 & 32.96 & 32.23 & 32.87 \\
\hline $\mathrm{A} 132$ & 34.98 & 37.26 & 33.41 & 33.65 \\
\hline A232 & 32.81 & 31.74 & 30.86 & 31.77 \\
\hline $\mathrm{A} 332$ & 32.81 & 31.74 & 30.86 & 31.77 \\
\hline
\end{tabular}

Table 7. Determination coefficients of the regressions between the estimated and simulated maternal genetic values (EVm $\times \mathrm{SVm}$ ) for each analysis and simulation set (S1 through S4), taking into consideration all the animals.

\begin{tabular}{|c|c|c|c|c|}
\hline \multirow[t]{2}{*}{ Combined analysis } & \multicolumn{4}{|c|}{ Simulation Set } \\
\hline & S1 & S2 & S3 & S4 \\
\hline & \multicolumn{4}{|c|}{ EVm x SVm } \\
\hline A112 & 0.94 & 0.24 & 0.78 & 0.22 \\
\hline A212 & 7.55 & 12.27 & 12.49 & 11.03 \\
\hline $\mathrm{A} 312$ & 5.44 & 8.43 & 8.06 & 9.51 \\
\hline A122 & 1.64 & 1.33 & 0.10 & 0.36 \\
\hline A222 & 11.31 & 15.47 & 19.25 & 15.18 \\
\hline $\mathrm{A} 322$ & 3.81 & 9.72 & 10.82 & 8.15 \\
\hline A132 & 1.68 & 2.07 & 0.25 & 0.42 \\
\hline $\mathrm{A} 232$ & 12.13 & 16.21 & 18.96 & 15.32 \\
\hline $\mathrm{A} 332$ & 12.13 & 16.21 & 18.96 & 15.32 \\
\hline
\end{tabular}

Genetics and Molecular Research 15 (4): gmr.15048382 
Table 8. Determination coefficients of the regressions between the estimated and simulated direct genetic value (EVd x SVd) for each analysis and simulation set (S1 through S4), taking into consideration only the animals for which observed production data were available.

\begin{tabular}{|c|c|c|c|c|}
\hline \multirow[t]{2}{*}{ Combined analysis } & \multicolumn{4}{|c|}{ Simulation set } \\
\hline & $\mathrm{S} 1$ & S2 & S3 & S4 \\
\hline & \multicolumn{4}{|c|}{ EVd x SVd } \\
\hline A111 & 52.60 & 52.01 & 50.84 & 51.02 \\
\hline A211 & 46.91 & 44.84 & 45.06 & 45.05 \\
\hline $\mathrm{A} 311$ & 46.12 & 46.25 & 44.52 & 46.35 \\
\hline $\mathrm{A} 121$ & 52.36 & 51.44 & 50.66 & 51.16 \\
\hline A221 & 46.41 & 46.24 & 44.00 & 45.94 \\
\hline A321 & 46.01 & 46.93 & 45.29 & 46.53 \\
\hline $\mathrm{A} 131$ & 51.87 & 50.83 & 49.89 & 50.73 \\
\hline A231 & 45.90 & 45.70 & 43.97 & 45.68 \\
\hline A331 & 45.90 & 45.70 & 43.97 & 45.68 \\
\hline A112 & 52.55 & 52.02 & 50.85 & 51.01 \\
\hline $\mathrm{A} 212$ & 49.10 & 47.26 & 45.78 & 47.60 \\
\hline $\mathrm{A} 312$ & 47.80 & 47.99 & 46.52 & 48.56 \\
\hline $\mathrm{A} 122$ & 52.35 & 51.42 & 50.66 & 51.15 \\
\hline A222 & 49.20 & 48.02 & 46.01 & 48.32 \\
\hline A322 & 49.21 & 48.84 & 47.95 & 49.11 \\
\hline A132 & 51.94 & 50.86 & 49.92 & 50.73 \\
\hline A232 & 49.07 & 47.59 & 46.56 & 48.04 \\
\hline A332 & 49.07 & 47.59 & 46.56 & 48.04 \\
\hline
\end{tabular}

Table 9. Determination coefficients of the regressions between the estimated and simulated maternal genetic value (EVm x SVm) for each analysis and simulation set (S1 through S4), taking into consideration only the animals for which observed production data were available.

\begin{tabular}{|c|c|c|c|c|}
\hline \multirow[t]{2}{*}{ Combined analysis } & \multicolumn{4}{|c|}{ Simulation set } \\
\hline & S1 & S2 & S3 & S4 \\
\hline & \multicolumn{4}{|c|}{ EVm x SVm } \\
\hline A112 & 0.98 & 0.47 & 2.06 & 0.92 \\
\hline $\mathrm{A} 212$ & 12.76 & 16.26 & 17.32 & 18.66 \\
\hline $\mathrm{A} 312$ & 11.78 & 8.68 & 12.24 & 15.19 \\
\hline $\mathrm{A} 122$ & 1.05 & 1.89 & 0.90 & 0.56 \\
\hline $\mathrm{A} 222$ & 16.04 & 19.84 & 22.74 & 20.67 \\
\hline $\mathrm{A} 322$ & 8.70 & 13.61 & 16.22 & 14.56 \\
\hline$\overline{\mathrm{A} 132}$ & 1.04 & 2.55 & 0.61 & 0.73 \\
\hline $\mathrm{A} 232$ & 16.10 & 20.42 & 22.32 & 20.77 \\
\hline A332 & 16.10 & 20.42 & 22.32 & 20.77 \\
\hline
\end{tabular}

Taking into consideration all the animals present in the file $(154,417)$ and examining Table 6, which presents the data simulated without maternal effects (A1xx), the inclusion of these effects in the 1st or 2nd stage of the analysis made little difference. Even in the situations under which the heritability was low (A122 and A132), the $\mathrm{R}^{2}$ values were similar.

In the analysis that did not include a maternal additive effect in the 2nd stage (Axx1), the incorporation of the maternal effect in the data simulation appeared to be the cause of the decreased $\mathrm{R}^{2}$ value between EVd and SVd. When the maternal additive effect was included in the 2nd stage, there was a smoothing of that loss, but the inclusion of the same effect in the 1st stage largely did not affect the results. Thus, it appears that controlling the additive maternal effects and correction for the non-additive maternal effects do not have significant effects on the prediction of the genetic values of the animals. 
Table 10. Determination coefficients of the regressions between estimated and simulated direct genetic values (EVd x SVd) for each analysis and simulation set (S1 through S4), taking into consideration only the bulls.

\begin{tabular}{|c|c|c|c|c|}
\hline \multirow[t]{2}{*}{ Combined analysis } & \multicolumn{4}{|c|}{ Simulation set } \\
\hline & S1 & S2 & S3 & S4 \\
\hline & \multicolumn{4}{|c|}{ EVd x SVd } \\
\hline A111 & 65.17 & 66.42 & 66.57 & 63.71 \\
\hline A211 & 65.26 & 54.59 & 53.29 & 56.29 \\
\hline A311 & 65.62 & 57.03 & 55.48 & 60.08 \\
\hline A121 & 64.44 & 65.20 & 65.27 & 63.34 \\
\hline A221 & 61.37 & 61.64 & 58.20 & 59.26 \\
\hline A321 & 58.99 & 60.11 & 57.31 & 57.77 \\
\hline A131 & 65.53 & 65.76 & 66.37 & 63.98 \\
\hline A231 & 62.24 & 61.83 & 59.96 & 59.98 \\
\hline A331 & 62.24 & 61.83 & 59.96 & 59.98 \\
\hline A112 & 65.22 & 66.46 & 66.63 & 63.33 \\
\hline A212 & 65.25 & 56.03 & 54.85 & 57.15 \\
\hline $\mathrm{A} 312$ & 66.11 & 58.07 & 56.59 & 59.61 \\
\hline A122 & 64.47 & 65.19 & 65.23 & 63.01 \\
\hline A222 & 60.05 & 63.71 & 60.41 & 60.51 \\
\hline A322 & 55.61 & 62.82 & 60.08 & 59.24 \\
\hline A132 & 65.43 & 65.73 & 66.26 & 63.38 \\
\hline $\mathrm{A} 232$ & 61.26 & 63.95 & 62.09 & 60.81 \\
\hline A332 & 61.26 & 63.95 & 62.09 & 60.81 \\
\hline
\end{tabular}

Table 11. Determination coefficients of the regressions between the estimated and simulated maternal genetic values $(\mathrm{EVm} \times \mathrm{SVm}$ ) for each analysis and simulation set (S1 through S4), taking into consideration only the bulls.

\begin{tabular}{l|c|c|c|c}
\hline \multirow{2}{*}{ Combined analysis } & \multicolumn{4}{|c}{ Simulation set } \\
\cline { 2 - 5 } & S1 & S2 & S3 & S4 \\
\hline & \multicolumn{4}{|c|}{ EVm x SVm } \\
\hline A112 & 1.27 & 0.03 & 0.15 & 0.14 \\
\hline A212 & 4.93 & 6.97 & 8.83 & 9.35 \\
\hline A312 & 3.25 & 5.21 & 6.24 & 7.23 \\
\hline A122 & 1.17 & 0.55 & 0.22 & 0.21 \\
\hline A222 & 8.00 & 9.20 & 13.50 & 10.78 \\
\hline A322 & 3.27 & 5.91 & 7.48 & 6.03 \\
\hline A132 & 1.11 & 0.59 & 0.33 & 0.20 \\
\hline A332 & 8.60 & 9.69 & 13.39 & 10.93 \\
\hline
\end{tabular}

With respect to maternal effects, the determination coefficients were very low, as expected in light of the estimated low heritability. The $\mathrm{R}^{2}$ value was higher when the maternal additive effect was included in the 1st stage model. Although, when the effect of maternal heterosis was used in the simulation, the $\mathrm{R}^{2}$ value decreased when the maternal effect was not taken into consideration in the analysis model and remained constant when it was taken into consideration.

Tables 8 and 9 present the determination coefficients between EVd x SVd and EVm $\mathrm{x}$ $\mathrm{SVm}$, respectively, for the group of animals for which the observed weight data were available among a total of 84,621 animals.

For the file that was composed only of animals with the observed production data, the $\mathrm{R}^{2}$ values were higher by $48 \%$ on average for direct effects than when all the animals present in the database were taken into consideration. The values for the regression between maternal values were slightly higher. However, the trend of the regression between the estimated and simulated genetic values (direct and maternal) was identical to that obtained when all the animals were taken into consideration. 
Similar to the two past files, the $\mathrm{R}^{2}$ of the bulls exhibited the same trend. The values of the coefficients were higher for the regression between the direct genetic values, although for the regressions between the maternal genetic values, the opposite occurred, resulting in lower values compared to the other two files.

\section{CONCLUSION}

The estimates of the additive effects of biological types were influenced by the maternal effects that were present in the population, and the estimates of non-additive effects had little influence, being well estimated in any situation, similar to the non-additive maternal effects.

The estimate of heritability was overestimated when the maternal effects present in the analyzed trait were ignored and should be taken into consideration in the analysis when the presence of maternal effects is suspected in the analyzed traits in this type of population.

The studied models estimate the direct genetic values well, demonstrating high coefficients of determination between the real and estimated values.

\section{Conflicts of interest}

The authors declare no conflict of interest.

\section{ACKNOWLEDGMENTS}

A.L. Bocchi received a scholarship from Fundação de Amparo à Pesquisa do Estado de São Paulo (FAPESP).

\section{REFERENCES}

Arnold JW, Bertrand JK and Benyshek LL (1992). Animal model for genetic evaluation of multibreed data. J. Anim. Sci. 70: 3322-3332.

Bocchi AL, Oliveira HN, Ferraz JBS and Eler JP (2008). Avaliação genética multirracial para ganho de peso pré-desmama em bovinos de uma população composta. Rev. Bras. Zootec. 37: 1207-1215. http://dx.doi.org/10.1590/S1516$\underline{35982008000700010}$

Boldman KG, Kriese LA, Van Vleck LD, Van Tassell CP, et al. (1995). A Manual for use of MTDFREML - a set of programs to obtain estimates of variances and covariances (DRAFT). U.S. Department of Agriculture, Agriculture Research Service, Lincoln, 115

Bueno RS, Torres RA, Ferraz JBS, Lopes PS, et al. (2012). Métodos de estimação de efeitos genéticos não-aditivos para características de peso e perímetro escrotal em bovinos de corte mestiços. Rev. Bras. Zootec. 41: 1140-1145. http:// dx.doi.org/10.1590/S1516-35982012000500009

Clément V, Bibé B, Verrier E, Elsen JM, et al. (2001). Simulation analysis to test the influence of model adequacy and data structure on the estimation of genetic parameters for traits with direct and maternal effects. Genet. Sel. Evol. 33: 369-395.http://dx.doi.org/10.1186/1297-9686-33-4-369

Ferraz JBS, Eler JP and Golden BL (1999). A formação do composto Montana tropical. Rev. Bras. Reprod. Anim. 23: 115-117.

Mourão GB, Ferraz JB, Eler JP, Bueno RS, et al. (2008). Non-additive genetic effects on weights and performance of a Brazilian Bos taurus x Bos indicus beef composite. Genet. Mol. Res. 7: 1156-1163. http://dx.doi.org/10.4238/vol74 gmr501

Näsholm A and Danell O (1996). Genetic relationships of lamb weight, maternal ability, and mature ewe weight in Swedish finewool sheep. J. Anim. Sci. 74: 329-339.

Pereira JCC (2001). Melhoramento genético aplicado à produção animal. 3rd ed. FEPMVZ, Belo Horizonte.

Quaas RL and Pollak EJ (1981). Modified equations for sire models with groups. J. Dairy Sci. 64: 1868-1872. http:// dx.doi.org/10.3168/jds.S0022-0302(81)82778-6

Genetics and Molecular Research 15 (4): gmr.15048382 
Robinson DL (1996). Models which might explain negative correlations between direct and maternal genetic effects. Livest. Prod. Sci. 45: 111-122. http://dx.doi.org/10.1016/0301-6226(96)00002-4

Rodríguez-Almeida FA, Van Vleck LD and Gregory KE (1997). Estimation of direct and maternal breed effects for prediction of expected progeny differences for birth and weaning weights in three multibreed populations. J. Anim. Sci. 75: 1203-1212.

SAS Institute (2004). SAS/STAT User's Guide, Version 9.1. SAS Institute, Cary.

Southwood OI, Kennedy BW, Meyer K and Gibson JP (1989). Estimation of additive maternal and cytoplasmic genetic variances in animal models. J. Dairy Sci. 72: 3006-3012. http://dx.doi.org/10.3168/jds.S0022-0302(89)79453-4

Waldron DF, Morris CA, Baker RL and Johnson DL (1993). Maternal effects for growth traits in beef cattle. Livest. Prod. Sci. 34: 57-70. http://dx.doi.org/10.1016/0301-6226(93)90035-G

Genetics and Molecular Research 15 (4): gmr.15048382 